American Journal of Civil Engineering
2020; $8(2): 20-29$
http://www.sciencepublishinggroup.com/j/ajce
doi: $10.11648 /$ jajce.20200802.11
ISSN: $2330-8729$ (Print); ISSN: $2330-8737$ (Online)

\title{
Finite Element Analysis of Reinforced Concrete Interior Beam Column Connection Subjected to Lateral Loading
}

\author{
Gemechu Abdissa \\ Department of Civil Engineering, Mizan-Tepi University, SNNPR, Tepi, Ethiopia \\ Email address: \\ gamif2011@gmail.com \\ To cite this article: \\ Gemechu Abdissa. Finite Element Analysis of Reinforced Concrete Interior Beam Column Connection Subjected to Lateral Loading. \\ American Journal of Civil Engineering. Vol. 8, No. 2, 2020, pp. 20-29. doi: 10.11648/j.ajce.20200802.11
}

Received: March 14, 2020; Accepted: March 30, 2020; Published: April 23, 2020

\begin{abstract}
The beam column connection is the most critical zone in a reinforced concrete frame. The strength of connection affects the overall behavior and performance of RC framed structures subjected to lateral load and axial loads. The study of critical parameters that affects the overall joint performances and response of the structure is important. Recent developments in computer technology have made possible the use of Finite element method for 3D modeling and analysis of reinforced concrete structures. Nonlinear finite element analysis of reinforced concrete interior beam column connection subjected to lateral loading was performed in order to investigate joint shear failure mode in terms of joint shear capacity, deformations and cracking pattern using ABAQUS software. A 3D solid shape model using 3D stress hexahedral element type (C3D8R) was implemented to simulate concrete behavior. Wire shape model with truss shape elements (T3D2) was used to simulate reinforcement's behavior. The concrete and reinforcement bars were coupled using the embedded modeling technique. In order to define nonlinear behavior of concrete material, the concrete damage plasticity (CDP) was applied to the numerical model as a distributed plasticity over the whole geometry. The study was to investigate the most influential parameters affecting joint shear failure due to column axial load, beam longitudinal reinforcement ratio, joint panel geometry and concrete compressive strength. The Finite Element Model (FEM) was verified against experimental test of interior RC beam column connection subjected to lateral loading. The model showed good comparison with test results in terms of load-displacement relation, cracking pattern and joint shear failure modes. The FEA clarified that the main influential parameter for predicting joint shear failure was concrete compressive strength.
\end{abstract}

Keywords: RC Beam Column Connection, Finite Element Model, Shear Strength, Joint Shear Failure, Crack Patterns

\section{Introduction}

Beam column connections are one of important structural elements in concrete structures. It is also a critical seismic element because its behavior under severe earth quake motions has a significant effect on failure mode and strength and deformation capacity of the building structures. When the building is subjected to the earth quake, beam column connection is prone to joint shear failure due to high shear stress which appears in the joint panel as result of opposite sign moments on opposite side of the joint core. The joint shear failure is a brittle type of failure which can strongly affect ductility of the RC frames. The early occurrence of this failure causes the building frames collapse without reaching their ultimate capacity. Beam column connections have been identified as potentially one of the weaker components when
RC Moment Resisting Frame (MRF) is subjected to seismic lateral loading. Since the mid-1960s, numerous experimental tests and numerical studies have been conducted to investigate the performance of $\mathrm{RC}$ beam column connections subjected to lateral loading [1-5]. When only the flexural strength of well detailed longitudinal beams limits over all response, RC BCCs typically display ductile behavior (with the joint panel region essentially remaining elastic). The failure mode wherein the beam forms hinges is usually considered to be the most desirable for maintaining good global energy dissipation without severe degradation of capacity at connections. Many Finite element analysis and experimental investigations have been done so far to understand beam column connection failure and resistant mechanisms. The analyses were either 2D or 3D spatial discretization with bond-slip or bond-lock bond behaviors models. Nonlinear finite element analysis on the RC 
beam column connection shear failure under cyclic lateral loading and monotonic loading have been conducted to investigate shear failure modes and post peak behaviors such as cyclic deterioration and shear resistance mechanisms in terms of shear capacity, deformation and crack pattern $[6,7]$.

In various countries like United States, New Zealand, Japan, Republic of Korea and others, many researchers has tried several approaches to improve understanding of RC joint shear behavior [7, 8]. Influence parameters on joint shear behavior have been examined using collected experimental test results and analytical procedures. However, there is no consensus about the effect of some parameters on joint shear strength. Thus, some design considerations for joint shear strength (and/or joint shear deformation), in addition, there is no generally accepted joint shear stress vs. joint shear strain prediction model that can be describe the complete joint shear behavior of diverse types of RC beam column connections [9-14]. Researchers have observed four types of failures that can take place in beam column connection [15]. These modes of failure can be classified as shear failure in the joint, slippage of the beam main reinforcement bars, yielding of the beam main reinforcement (beam hinging) and yielding of the column longitudinal bars (column hinging). Shear failure of beam column connection was the main cause in failure of several moment-resisting frame structures during recent earthquakes $[15,16]$.

The strength of beam column joints have long been recognized as a significant factor that affects the overall behavior of RC moment resisting frames subjected to large lateral loading. The reversal of forces in opposite direction in BCC during earth quake may cause distress which often results in failure when not designed and detailed in proper manner. The behavior of the joints when subjected to large forces and severe ground shaking during the earth quake determines the response of the whole structure. The assumption of joint being rigid fails to consider the effect of high shear force developed within the joint. The shear failure developed within the rigid joint is always brittle in nature which is not acceptable in seismic design of frames subjected to seismic loads $[17,18]$.

\section{Materials and Methods}

\subsection{Model Geometry and Size}

Finite element modeling of RC conventional interior joint shear behavior calibrated by experimental results of other researcher was the main strategy of this study. To verify the model, interior beam column joint configurations are modeled and simulated. To represent non-ductile detail of the joint, no transverse reinforcement was considered within the joint panel interior joint. The numerical modeling is calibrated by experimental results of cyclic lateral loading test on interior done by [5].

\subsection{Modeling and Analysis}

The material properties used to conduct the experiment are used to model the beam column joint so that the study parameters clearly define the joints. The configuration of numerical model is implemented in finite element code ABAQUS. The finite element model is validated with experimental results. Finite Element Analysis (FEA) of the connection specimens is performed in a nonlinear static analysis format and the analysis procedure considers both material and geometric nonlinearities. In a nonlinear analysis, the total specified loads acting on a finite element body will be divided into a number of load increments [5]. At the end of each increment the structure is in approximate equilibrium and the stiffness matrix of structure will be modified in order to reflect nonlinear changes in structure's stiffness.

\subsection{Test setups, Boundary Conditions, Loading, Dimensions, and Details}

The schematic test setups, reaction frames, specimen and loading system were shown in figure 1 . The beams and columns were pinned at their ends to simulate points of inflection. The pins at the end of the beams were supported by vertical steel links that restrained only vertical displacements at the beam ends. The column was pin supported at its base and deflected laterally at its tip. Onplane movement of the specimen was prevented by two braced I-sections connected to the reaction frame [5].

The specimen was tested under constant axial load $230 \mathrm{KN}$, which is the total specified load acting on a finite element body and will be divided into a number of load increments, applied on the column and quasi static cyclic lateral loading at column's tip to simulate earthquake loading. The load was applied by means of three hydraulic actuators with $1000 \mathrm{KN}$ capacity and a stroke of $\pm 150 \mathrm{~mm}$. The selected lateral load history consisted of two phases. The first phase was forcecontrol and the second phase was displacement control. At early stage of the first phase of the loading, two cycles approximately $10 \%$ of the theoretical yield load of the beam was applied to check the test setup and ensure that all data acquisition channels were functioning properly.

Table 1. Material Properties of the test.

\begin{tabular}{|c|c|c|c|c|c|c|c|c|}
\hline $\begin{array}{l}\text { Connection } \\
\text { type }\end{array}$ & $\begin{array}{l}\text { Concrete compressive } \\
\text { strength }(M p a)\end{array}$ & $\begin{array}{l}\text { Tensile strength } \\
\text { Concrete }(M p a)\end{array}$ & $\begin{array}{l}\text { Reinforcement type: } \\
\text { Longitudinal and stirrup }\end{array}$ & $\begin{array}{l}\text { Bar dia } \\
(\mathrm{mm})\end{array}$ & meter & $\begin{array}{l}\text { Yield strength } \\
(M p a)\end{array}$ & $\begin{array}{l}\text { Modulus of } \\
\text { Elasticity, E (Mpa) }\end{array}$ & $\begin{array}{l}\text { Yield strain } \\
\text { (for steel) }\end{array}$ \\
\hline \multirow{5}{*}{ Interior } & \multirow{5}{*}{34.32} & \multirow{5}{*}{2.84} & \multirow{2}{*}{ Beam } & Top & 16 & 497.64 & 202,405 & 0.00247 \\
\hline & & & & Bottom & 14 & 345.38 & 202,405 & 0.00171 \\
\hline & & & \multirow{2}{*}{ Column } & Top & 16 & 497.64 & 202,405 & 0.00247 \\
\hline & & & & Bottom & 14 & 345.38 & 202,405 & 0.00171 \\
\hline & & & Stirrup & & 8 & 345.38 & 195,733 & 0.00171 \\
\hline
\end{tabular}




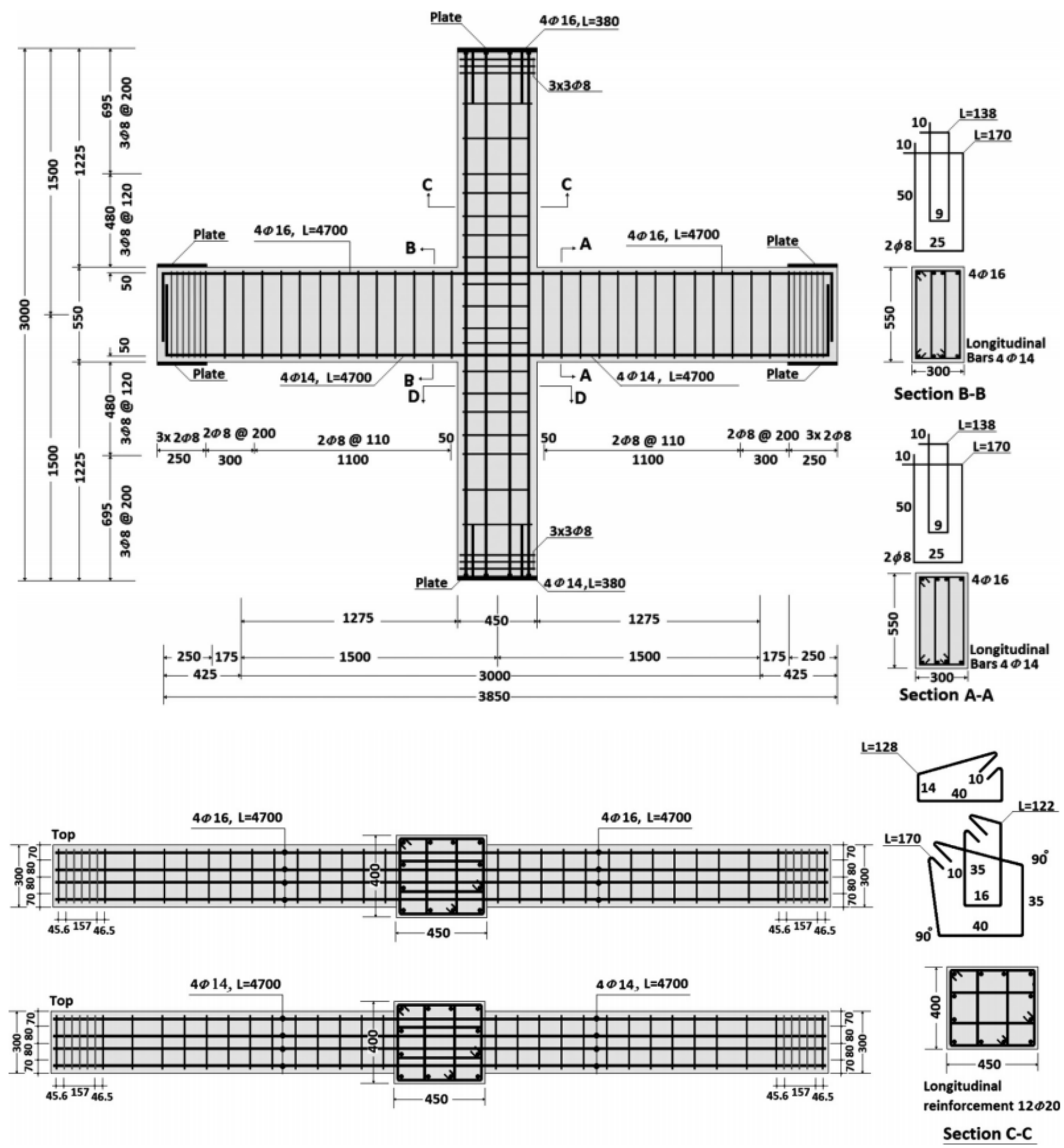

Figure 1. Dimension and Reinforcement Details.

Table 2. Modeling of material Properties.

\begin{tabular}{lllll}
\hline Material & & Density $\left(\mathbf{t o n n} / \mathbf{m m}^{\mathbf{3}}\right)$ & Youngs modulus of elasticity (Mpa) & Poisson's ratio \\
\hline Concrete & & $2.54 \mathrm{e}-9$ & 31848 & 0.2 \\
\multirow{2}{*}{ Steel } & Rebar & $7.85 \mathrm{e}-9$ & 202405 & 0.3 \\
& Stirrup & $7.85 \mathrm{e}-9$ & 195733 & 0.3 \\
\hline
\end{tabular}




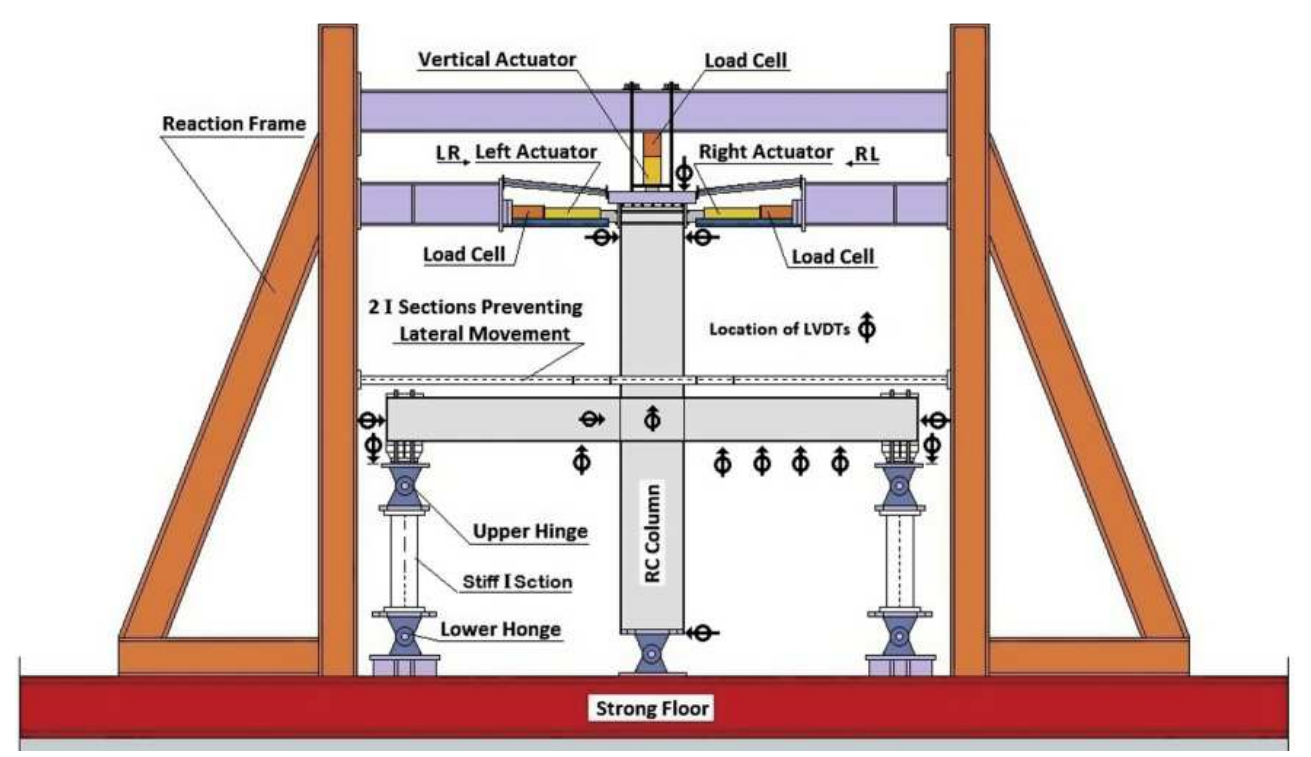

Figure 2. Schematic test setup for the specimen.

\subsubsection{Modeling of Concrete Properties}

a) Concrete compressive uniaxial stress-strain behavior

The concrete stress-strain behavior under compression was categorized and modeled in three phases [2, 5, 6, 7].

Phase 1: This stage is linear-elastic phase. It is continuous up to about $40 \%$ of the maximum compressive stress level $\sigma_{c o}=0.4 f_{c}{ }^{\prime}$.

$$
\sigma_{c, 1}=E_{c} \varepsilon_{c}, \varepsilon_{c} \leq 0.4 f_{c}^{\prime} / E_{c}
$$

Phase 2: This stage is the hardening phase. At this phase the stress increases gradually until it reaches a strain level of 0.0035 . It describes the ascending branch of the stress strain relationship reaching the peak stress, $\sigma_{c u}$ at corresponding strain level $\varepsilon_{o}=2 f_{c}{ }^{\prime} / E_{c}$ where $\eta_{c}$ is material constant obtained from the relation of phase 1 and 2 .

$$
\sigma_{c, 2}=\frac{\eta_{c} \frac{\varepsilon_{c}}{\varepsilon_{o}}-\left(\frac{\varepsilon_{c}}{\varepsilon_{o}}\right)^{2}}{1+\left(\eta_{c}-2\right) \frac{\varepsilon_{c}}{\varepsilon_{o}}} f_{c}{ }^{\prime}, \quad 0.4 f_{c}{ }^{\prime} / E_{c} \leq \varepsilon_{c} \leq 0.0035
$$

Phase 3: This stage is post peak softening phase. It represents the initiation and progression of compressive damage in the concrete material until the ultimate compressive strain $\varepsilon_{u}$ attained. The stress-strain compatibility at stress level of $\sigma_{c o}=0.4 f_{c}{ }^{\prime}$. Using the stress-strain compatibility at strain level of $\varepsilon_{c u}=0.0035$ for phase 1 and 2 , gives the value of $\lambda_{c}$ which represents constant crushing energy as material property. [2] Uses data in terms of inelastic strain ${\widetilde{\varepsilon_{c}}}^{i n}=\varepsilon_{c}-\left(\sigma_{c} / \mathrm{E}_{c}\right)$ which is total strains minus elastic strains corresponding to undamaged material. Figure shows concrete uniaxial compressive stress-strain behavior used in the model.

$$
\begin{gathered}
\sigma_{c, 3}=\left(\frac{2+\lambda_{c} f_{c}{ }^{\prime} \varepsilon_{o}}{2 f_{c}{ }^{\prime}}-2 \lambda_{c} \varepsilon_{o}+\frac{\lambda_{c} \varepsilon_{c}{ }^{2}}{2 \varepsilon_{0}}\right)^{-1}, \\
0.0035 \leq \varepsilon_{c} \leq 0.03
\end{gathered}
$$

$$
d_{c}=1-\frac{\sigma_{c}}{E_{0}\left(\varepsilon_{c}-\varepsilon p_{c}\right.}
$$

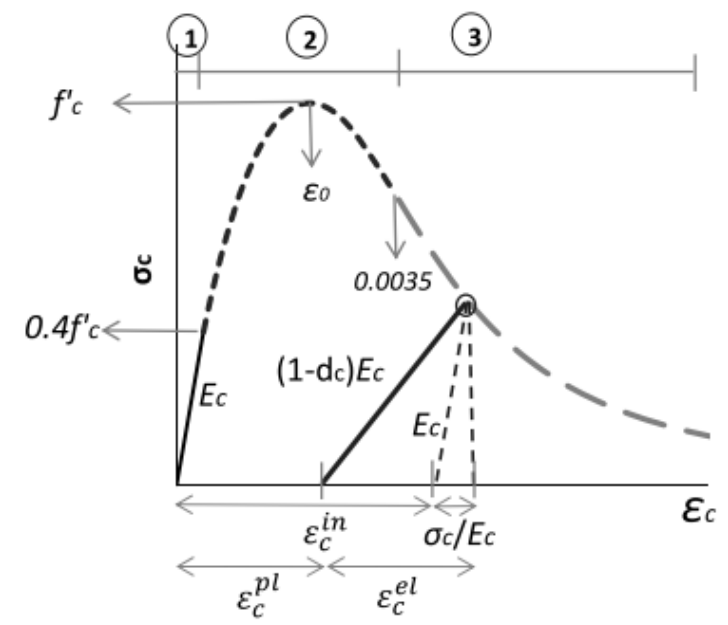

Figure 3. Concrete compressive uniaxial stress-strain behavior [2].

b) Concrete tensile uniaxial stress-strain behavior

$$
d_{t}=1-\frac{\sigma_{t}}{E_{o}\left(\varepsilon_{t}-\varepsilon^{p l} t\right.}
$$

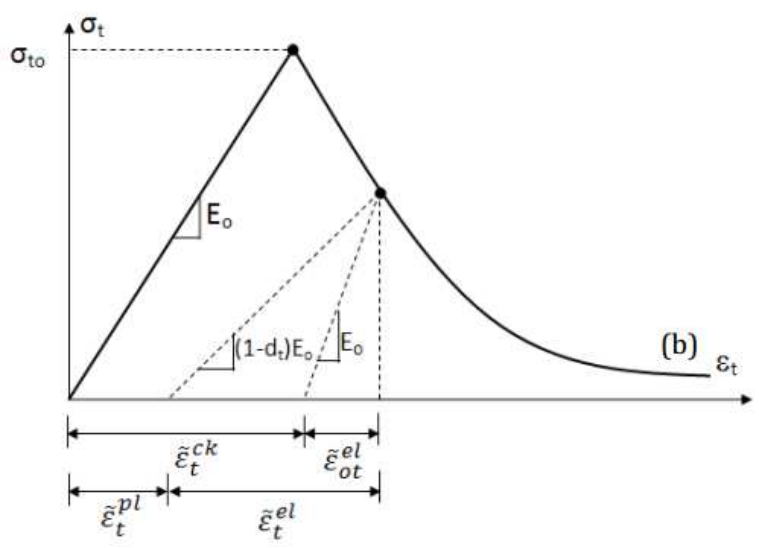

Figure 4. Concrete tensile uniaxial stress-strain behavior [2]. 
c) Uniaxial tensile stress-crack width relationship for concrete

The concrete behavior in tension for normal weight concrete is characterized by a stress crack displacement response as shown in figure 5 .

$$
G_{f}=G_{f 0}\left(\left(f_{c}^{\prime}+8\right) /\left(f_{c m o}\right)^{0.7}\right.
$$

Where $G_{f}$-fracture energy of concrete that represents the area under the tensile stress crack displacement curve $(\mathrm{N} / \mathrm{m})$

$f_{t}$-maximum tensile strength

$G_{f 0}=0.03 \mathrm{~N} / \mathrm{mm}$-base fracture energy that depends on the maximum aggregate size

$$
f_{c m o}=10 \mathrm{MPa}
$$

Tension damage for post cracking behavior is obtained from tensile stress failure and fracture energy by specifying the tensile damage variable as a function of cracking displacement (w).

\subsubsection{Modeling of Reinforcement Properties}

The plastic properties of the reinforcement were determined based on the bilinear strain hardening yield stress-strain plastic strain curve. The load buckling of the reinforcing bar and the Bauschinger effect was not considered in steel material properties [8].

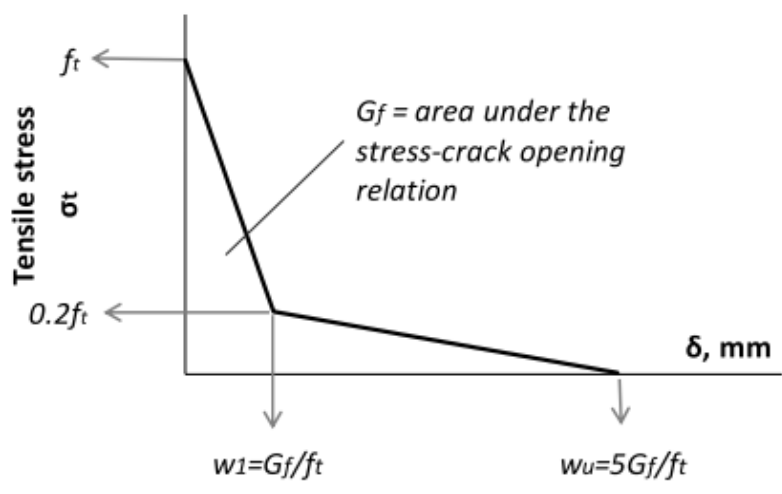

Figure 5. Uniaxial tensile stress-crack width relationship for concrete [9].

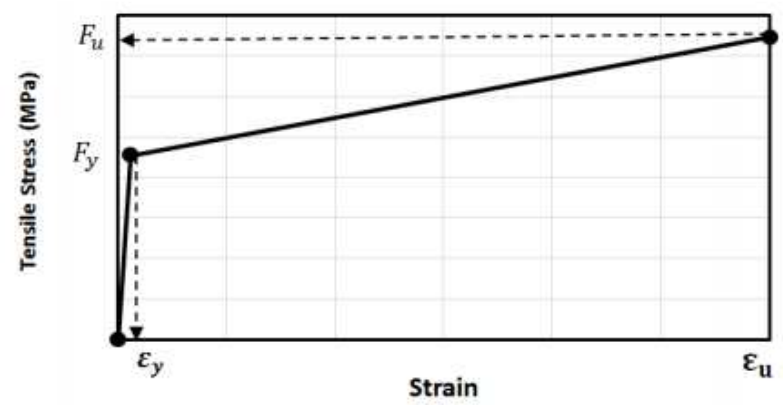

Figure 6. Reinforcement uniaxial stress-strain behavior

Table 3. Element type and shape.

\begin{tabular}{llll}
\hline Material & Element type & Element shape & Geometrical Order \\
\hline Concrete & C3D8R & Hexahedral & Linear \\
Reinforcement & T3D2 & Line & Linear \\
\hline
\end{tabular}

\begin{tabular}{|c|c|c|c|c|c|}
\hline Plasticity parameter & Dilation angle & Eccentricity & Stress ratio & Shape factor & Viscosity Parameter \\
\hline Value used in the model & 38 & 1 & 1.12 & 0.6667 & 0.01 \\
\hline
\end{tabular}

Table 4. Concrete damage plasticity (CDP) input parameters.

\subsection{Finite Element Analysis}

The static analysis in ABAQUS/Standard with viscosity regularization was performed. For solving this model using ABAQUS/Standard, a full Newton solver with default matrix storage was used. An automatic incremental with a small time step size and a large maximum number of increments were used to the convergence rate. A 3D solid shape model using 3D stress hexahedral element type (C3D8R) implemented to simulate concrete behavior. Wire shape model with truss elements (T3D2) is to simulate reinforcement's behavior. A uniform mesh size was chosen for concrete elements for the whole geometry and the same size for reinforcement mesh was adopted for steel bar. The size of elements is refined several times in order to obtain converged solution.

\section{Results and Discussion}
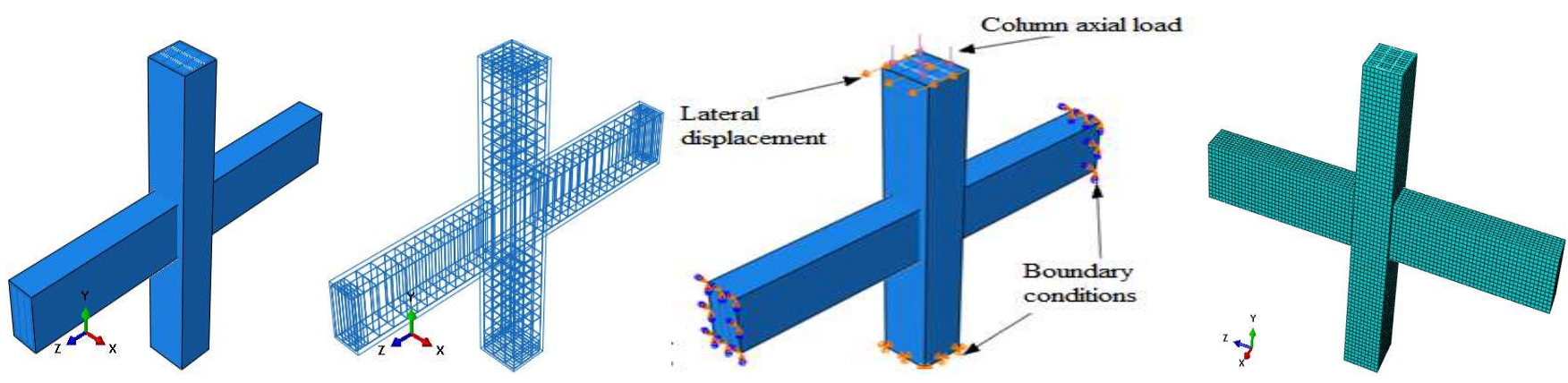

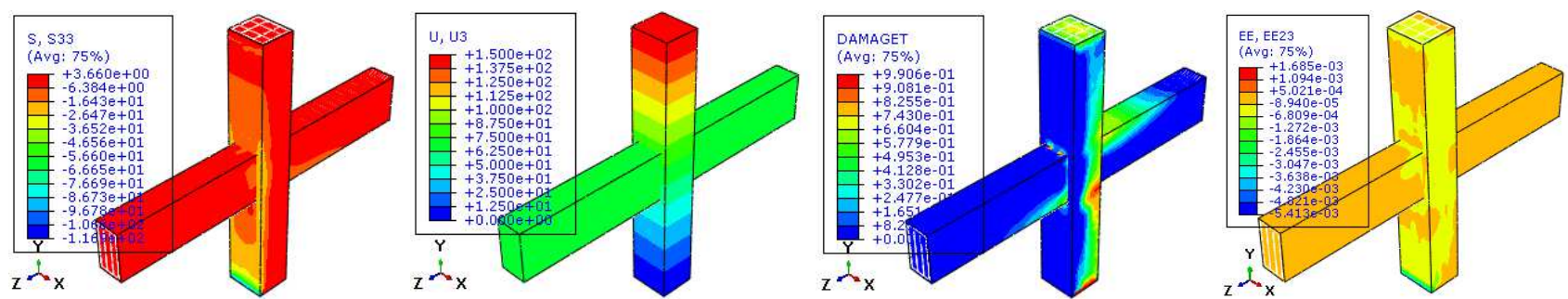

Figure 7. FEA results of $R C$ interior beam column connection.

\subsection{Verification of Finite Element Model}

To verify the Finite element model, the force-displacement curve obtained from finite element simulation is compared with the trace of the envelop behavior of the structure under cyclic loading reported [5].

Table 5. Peak lateral load and displacement of FEA and Experiments.

\begin{tabular}{lllll}
\hline Experimental results & & FEA results & & Difference (\%) \\
\hline Peak lateral load $(\mathrm{KN})$ & Peak lateral displacement $(\mathbf{m m})$ & Peak lateral load $(\mathrm{KN})$ & Peak lateral displacement (mm) & 4 \\
\hline 189.71 & 95.45 & 197.66 & 45.2 & 4 \\
\hline
\end{tabular}

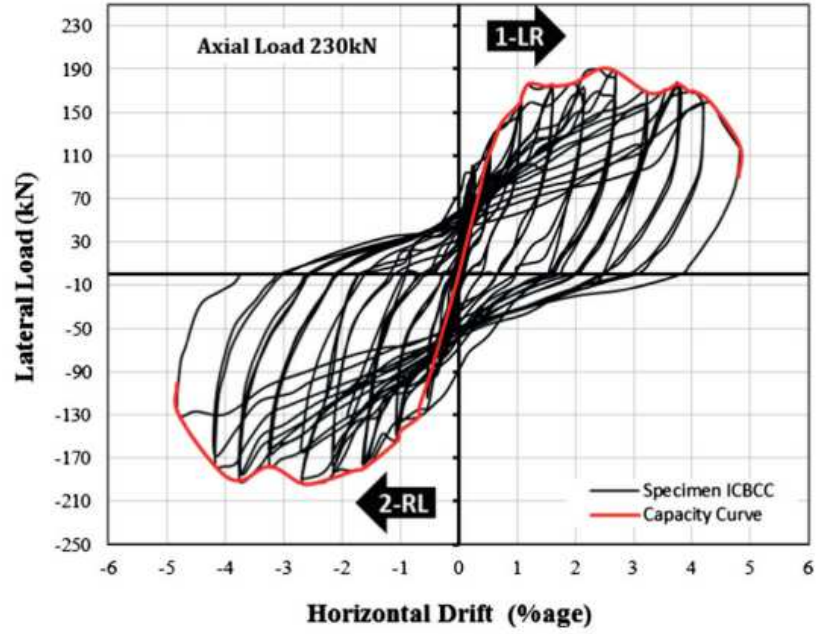

Figure 8. Experimental Load- displacement curve of Interior connection due to cyclic loading.

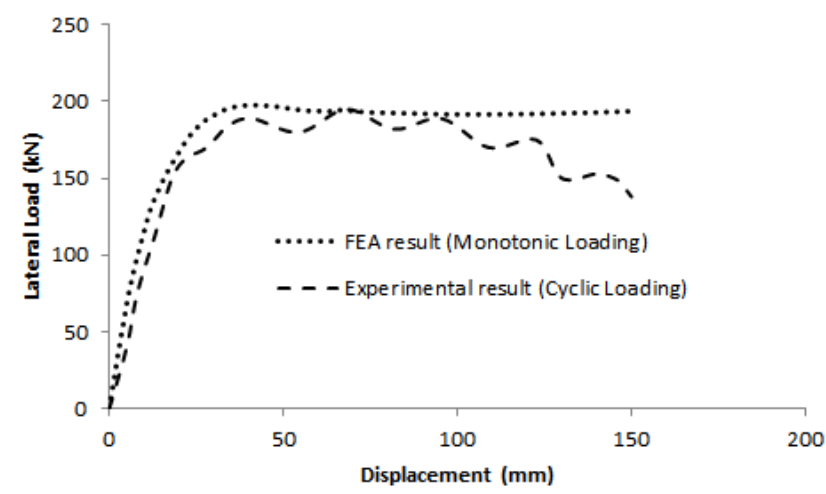

Figure 9. Comparison of numerical and experimental results.

The force-displacement graph obtained from the Finite element simulation and experimental result reported by [5] shows good agreement which verifies accuracy of finite element model. It can be understood from the two graphs that finite model prediction in elastic domain is a little lower than experimental test. It is shown that the difference in peak load in FEA and experimental test in interior beam column connection is $4 \%$, As illustrated in figure, the lateral force displacement curve predicted by the FEA follows most of the experimental curve closely.

\subsection{Key Points of the Joint Shear Failure}

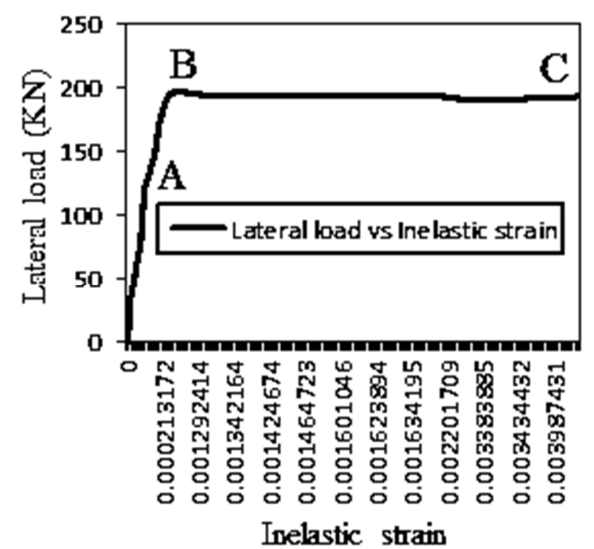

Figure 10. Lateral-displacement and Lateral load-strain relation for interior connection.

The cyclic overall or local behaviors can be reasonably represented as envelope curves by linearly connecting points A, $\mathrm{B}$ and $\mathrm{C}$, which display the most distinct stiffness changes as shown in Figure 10. The locations displaying distinct stiffness changes in Lateral load vs. Joint shear strain shows the overall and local behavior $[9,11]$. Thus the formation of new damage around a joint panel also initiates distinct stiffness changes in overall behavior and joint shear stresses can be calculated using the lateral load values at points $\mathrm{A}, \mathrm{B}$, and $\mathrm{C}$ of overall behavior. Significant concrete cracking, reinforcement yielding, and/or concrete crushing represent the formation of new damage within the joint panel. The stiffness change (point A) is caused by the initiation of diagonal cracking within the joint panel. Additional stiffness change may be occurring at (point B) from the yielding of reinforcement before the initiation of 
concrete crushing (point $\mathrm{C}$ ). In both types of connections and for all failure modes, after concrete crushing occurred within the joint panel (at point $\mathrm{C}$ ), the joint shear resistance was usually reduced which limited the overall capacity and initiates lateral load decrease.

For interior and exterior beam column connections, the columns are typically subjected to constant axial force during testing; column axial stress and strain can therefore be considered as constant values up to the cracking point.

Deformation of the joint panel in RC beam column connections determines the story deflection of overall frames. When overall response is governed by the joint shear, the contribution of the joint panel to the overall story deflection increases which indicates the joint shear deformation has a significant impact on over all story deflection and that overall ductile responses cannot necessarily guaranteed.

\subsubsection{Initiation of Diagonal Cracking Within the Joint Panel (point A)}

Joint shear stress $\left(v_{j}\right)$ and shear strain $(\gamma)$ can be obtained by applying three coordinate transformations if shear stress or shear strain is known.

$$
\begin{gathered}
v_{\mathrm{j}}(\text { cracking })=\sqrt{\sigma_{\mathrm{x}} \sigma_{\mathrm{y}}-\sigma_{\mathrm{x}} \sigma_{\mathrm{t}}-\sigma_{\mathrm{y}} \sigma_{\mathrm{t}}+\sigma_{\mathrm{t}}^{2}} \\
v_{\mathrm{j}}(\text { cracking })=\sqrt{\varepsilon_{\mathrm{x}} \varepsilon_{\mathrm{y}}-\varepsilon_{\mathrm{x}} \varepsilon_{\mathrm{t}}-\varepsilon_{\mathrm{y}} \varepsilon_{\mathrm{t}}+\varepsilon_{\mathrm{t}}{ }^{2}}
\end{gathered}
$$

Where $\sigma_{\mathrm{x}}-$ beam average axial stress

$\varepsilon_{\mathrm{x}}$-beam average axial strain

$\sigma_{\mathrm{y}}-$ column average axial stress

$\varepsilon_{\mathrm{y}}$ - column average axial strain

$\sigma_{\mathrm{t}}$-joint principal tensile stress

$\varepsilon_{\mathrm{t}}$-joint principal tensile stress

In the above equation tensile stress and strain are positive values whereas compressive stress and strain are negative values. The angle of inclination of the principal strains with respect to the $\mathrm{x}$-axis is the same as the angle of inclination of the principal stresses to the $\mathrm{x}$-axis. These principal stresses were assumed for the stress and strain of the concrete tensile strength because point A corresponds to initiation of diagonal cracking within the joint panel. For both interior and exterior connections, the columns are typically subjected to constant axial load. Therefore, column axial stress and strain can be considered as constant values up to the cracking point.

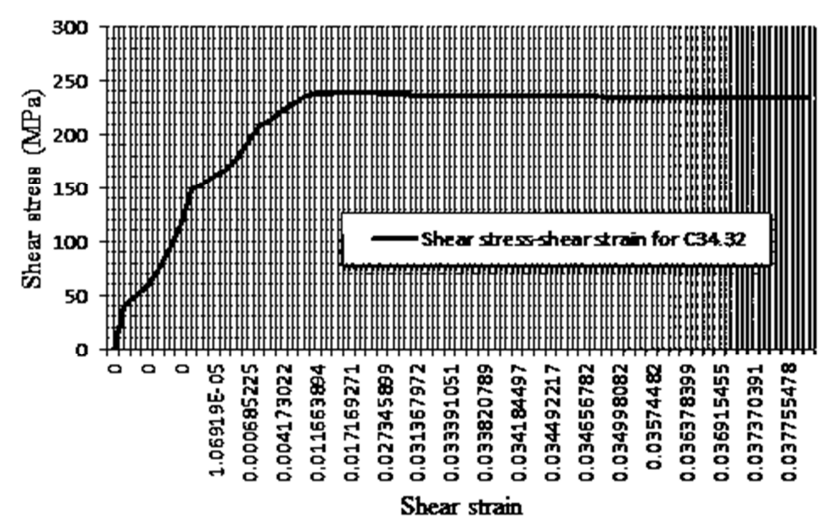

Figure 11. Shear stress-shear strain relation.
According to the CDP model, the concrete cracking is initiated when the maximum principal plastic strain is positive with the direction of the vector normal to the crack plane, parallel to the direction of maximum principal plastic strain. To find the beam and column axial stress at cracking, the joint shear stress was calculated for a given column shear by using force and moment equilibrium along with a freebody diagram at the mid-height of the joint panel. Then this joint shear stress can be compared to the joint shear stress calculated from cracking equations. Then, this joint shear stress was compared to the joint shear stress calculated from these equations; the column shear was continuously increased until the joint shear stress from equilibrium was equal to the joint shear stress from cracking equations. Finally, then, beam and column axial stress and strain could be determined.

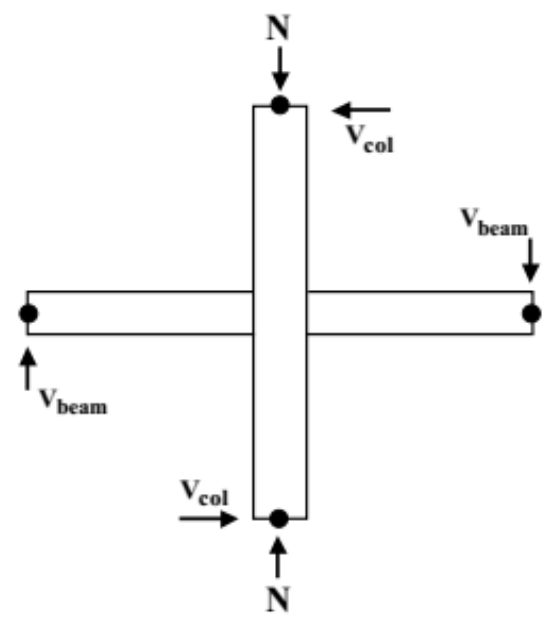

(a) Loading condition
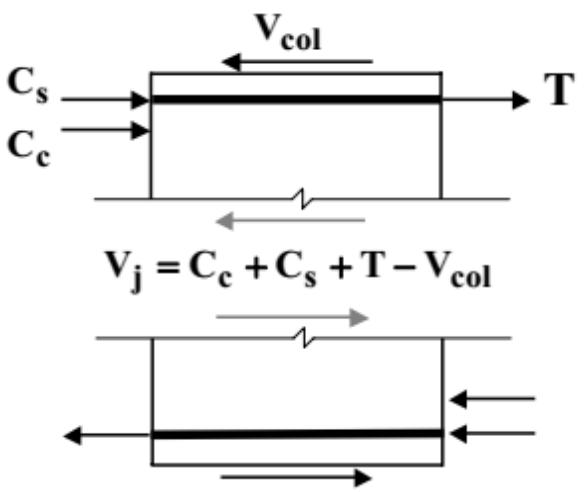

(b) Free-body diagram at the mid-height of interior connections

Figure 12. Loading condition and free-body diagram.

\subsubsection{Assessment of influence parameters (at $B$ and $C$ )}

\section{(i). Influence of Concrete Compressive Strength}

An increase in concrete compressive strength initiated an improvement of the joint shear resistance that comes from force transfer to the joint panel by bearing (from beam and column compression zones), and also that coming from bond between reinforcement and surrounding concrete. 
Compressive strength is the most influential parameter for joint shear stress at point B and C. Joint shear stress had similar relations to the square root of compressive strength at identified key points for both interior and exterior connections. The correlation coefficient at point $\mathrm{B}$ is 0.876 and 0.969 at point $\mathrm{C}$ for exterior, and 0.824 at Point $\mathrm{B}$ and 0.832 at point $\mathrm{C}$, for interior.

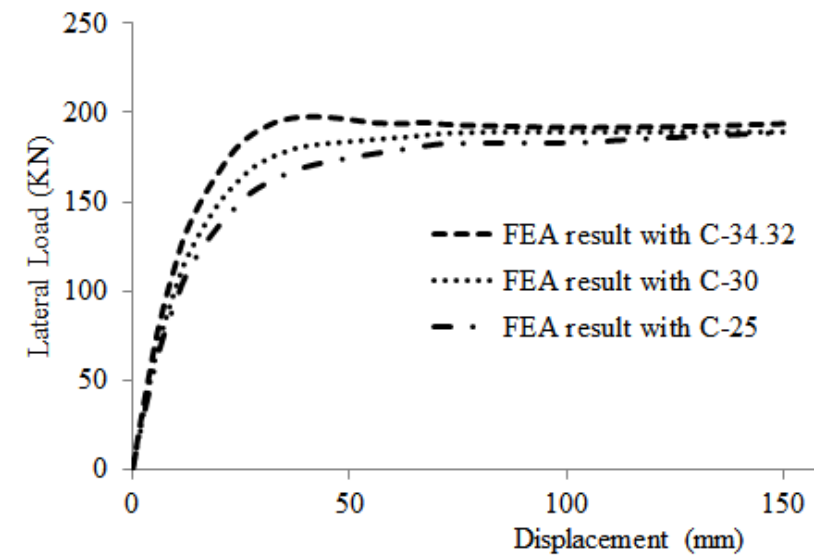

Figure 13. Influence of concrete compressive strength.

\section{(ii). Influence of Joint Aspect Ratio $\left(h_{b} / h_{c}\right)$}

The ratio of beam height to column depth $\left(h_{b} / h_{c}\right)$ is used to examine whether the shape of the joint panel in-plane direction dimensions might affect the joint shear behavior. The column width and depth, and beam width fixed constant while beam depth changes. The data base ranges from 0.875 to 1.375 for interior joint. At point $\mathrm{B}$, the joint shear stresses strains were little influenced by joint panel geometries for interior joint. However, at point $\mathrm{C}$, increase or decrease in joint aspect ratio will not affect the shear strength because it depends on the smooth path of shear transfer between column and beam. For $h b / h c=1.0$, shear resistance cpacity reduced slowly at phase of initiation of concrete crushing because there was smooth shear transfer between beam and column. Thus, ultimate shear resistance capacity of the joint was attained at early stage of concrete crushing. Shear resistance capacity reduces slowly before concrete starts to crush. At point $\mathrm{C}$, shear strength slowly increases. Thus, ultimate shear resistance capacity of the joint was attained at yielding of reinforcement

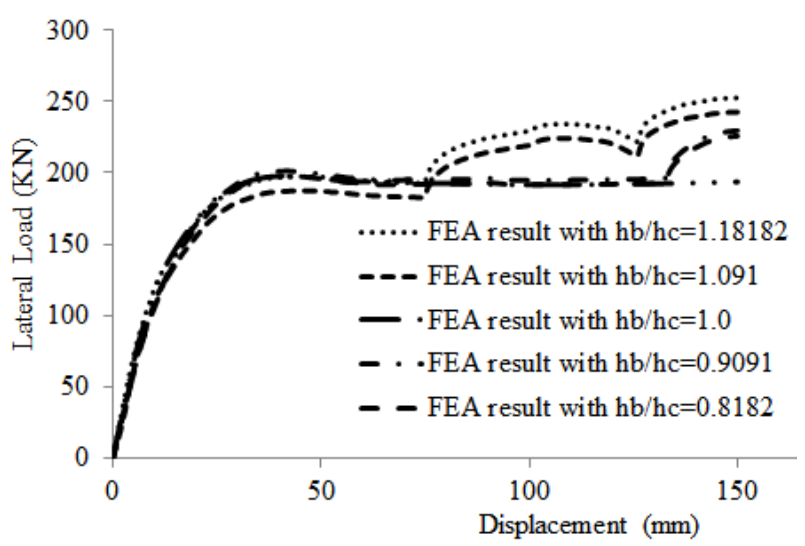

Figure 14. Influence of joint aspect ratio $\left(h_{b} / h_{c}\right)$.

\section{(iii). Influence of Column Axial Load}

The effect of column axial load on the seismic response of interior conventional beam column joints is that shear strength and stiffness of interior joints is not significantly affected by compressive column axial load. The shear strength and overall joint shear failure of interior beam column connections is not significantly affected for increase the compressive column axial load up to $7.6 \%\left(f^{\prime}{ }_{c} \mathrm{Ag}\right)$. Many previous experimental data bases for beam column joints without joint transverse reinforcement showed that shear strength of joints would not be affected for axial load less than $20 \%\left(f^{\prime}{ }_{c} A g\right)$, and after which increase in column axial load reduces the stiifness and strength. Therefore, column axial load is not a key influencing parameter of shear strength of RC beam column connections subjected lateral cyclic loading.

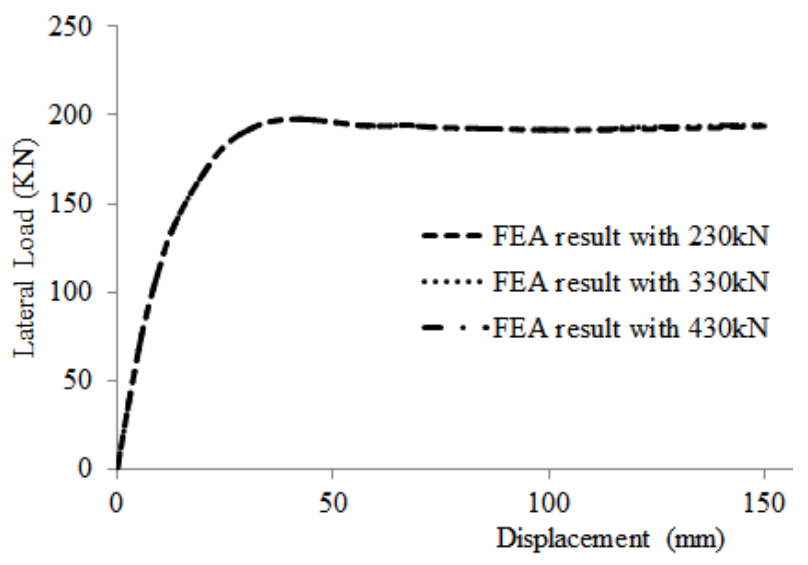

Figure 15. Influence of column axial load.

\section{(iv). Influence of Beam Longitudinal Reinforcement Ratio}

Joint shear strength is affected by the amount of longitudinal reinforcement provided in flexural beam for joints without joint transverse reinforcement. The increase of beam longitudinal reinforcement ratio leads to the increase of the horizontal joint shear force without yielding of beam longitudinal bars i.e. larger horizontal shear force is imposed with less deterioration of bond resistance around the beam longitudinal bars in the joint region which produces a wider diagonal strut which can carry the larger horizontal joint shear force. Increasing the beam longitudinal reinforcement ratio changes the failure type from a ductile failure (beam flexural failure) to a brittle one (joint shear failure). It is shown that the beam longitudinal reinforcement ratio affects the shear strength for BJ (the failure occurs around joint face extending to longitudinal beam) failure only. Thus, beam longitudinal beam reinforcement ratio may not be an influencing parameter in predicting the shear strength of beam column joints.

\subsection{Effect of Mesh Size on Finite Element Analysis Results}

When the material exhibits softening, finite element size influences significantly the entire model behavior due to localization since the dissipated energy decreases upon mesh refinement. 


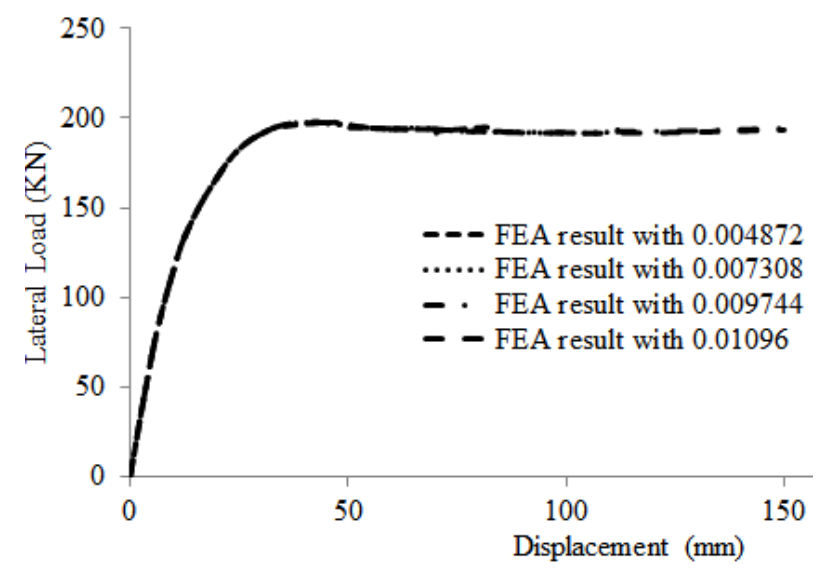

Figure 16. Influence of beam longitudinal reinforcement ratio.

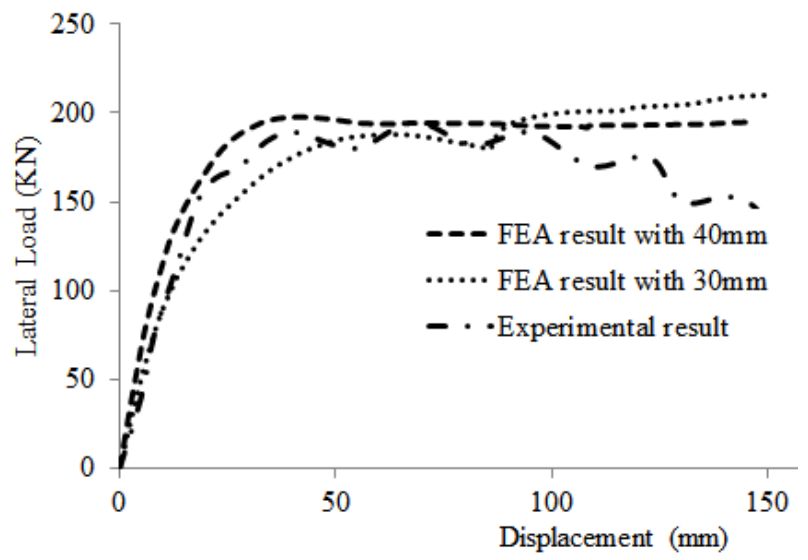

Figure 17. Load-displacement response for 30mm and 40mm mesh sizes.

\section{Conclusion}

The most influential parameters on joint shear behavior at identified distinct stiffness change due to initiation of diagonal cracking (point $\mathrm{A}$ ), second distinct stiffness change due to yielding of reinforcement (point B) and maximum response and initiation of concrete crushing (Point $\mathrm{C}$ ) have been analyzed using conventional interior $\mathrm{RC}$ beam column connections exhibiting joint shear failure. The data base for both RC beam column connections did not include the joint transverse reinforcement and out-of plane members such as transverse beams and slabs. Based on the assessement of influence parameters on joint shear failure, the most important results can be summerized as follows.

For initiation of diagonal cracking (at point A) for interior connections, the joint shear stress and strain can directly calculated by using stress/strain coordinate transformation based on principal stress and strain. The principal tensile stresses and tensile strains were assumed to be the stress and strain corresponding to concrete tensile strength.

At yielding of reinforcement (at point B) and initiation of concrete crushing (point $\mathrm{C}$ ), the concrete compressive strength was the most influential parameter of the overall joint shear stress and strain behavior.

The shear strength and overall joint shear failure of interior beam column connections is not significantly affected for increase the compressive column axial load up to $7.6 \%\left(f^{\prime}{ }_{c} A g\right)$. Many previous experimental data bases for beam column joints without joint transverse reinforcement had showed that shear strength of joints would not be affected for axial load less than $20 \%\left(f^{\prime}{ }_{c} A g\right)$, and after which increase in column axial load reduces the stiifness and strength.

For the same amount of longitudinal reinforcement, constant beam width and column width, in interior beam column joint, the increase in joint aspect ratio results in decrease in shear strength before yielding of reinforcement. For $h b / h c=1.0$, shear strength reduced slowly at initiation phase of concrete crushing. At point $\mathrm{C}$, increase or decrease in joint aspect ratio will not affect the shear strength because it depends on the smooth path of shear transfer between column and beam.

The increase of beam longitudinal tension reinforcement ratio didn't show a significant change in shear strength for addition of small amount of tensile reinforcement. However, the cracking pattern slightly changed from the edge of the beam to the column edge. It has also improved shear resistance capacity at the crushing stage of concrete. Thus, beam longitudinal beam reinforcement ratio may not be an influencing parameter in predicting the shear strength of beam column joints. It is shown that the beam longitudinal reinforcement ratio affects the shear strength for BJ (the failure occurs around joint face extending to longitudinal beam) failure only.

In this study, finite element analysis results confirmed the capability of the developed finite element model to predict the RC beam column connections subjected to joint shear behavior.

\section{Acknowledgements}

This research was financially supported by Ministry of Education, Ethiopia.

\section{References}

[1] Park, S., and Mosalam, K. M., (2012). Parameters for shear strength Prediction of exterior beam-column joints without transverse Reinforcement. Engineering Structures 36: 198209.

[2] Behnam, H., Kuang, J. S, Bijan, S. (2018). Parametric finite element analysis of RC wide beam column connections, Computers and structures 205: 28-44.

[3] Ravi, Kiran, and Giovacchino Genesio. (2014). A case study on pre 1970s constructed concrete exterior beam-column joints. Case Studies in Structural Engineering 1: 20-25.

[4] Masi A, Santarsiero G, Mossucca A, Nigro D. (2014). Influence of axial load on the seismic behavior of RC beamcolumn joints with wide beam. Applied Mechanics of Materials; Trans Tech Publications 508: 208-214.

[5] Fadwa I, Ali TA, Nazih E, Sara M. (2014). Reinforced concrete wide and conventional beam-column connections subjected to lateral load. Engineering Structures 76: 34-48. 
[6] Niroomandi, A., Najafgholipour, M. A., Ronagh, H. R. (2014). Numerical investigation of the affecting parameters on the shear failure of Non-ductile RC exterior joints, Engineering Failure Analysis 46: 62-75.

[7] LaFave, J. M. and Wight, J. K. (2001). Reinforced concrete wide beam-column connections vs. conventional construction: Resistance to lateral earthquake loads. Earthquake Spectra 17: 479-505.

[8] ABAQUS Analysis user's manual 6.14-EF (2014). Dassault Systems Simulia Corp. Providence, RI, USA.

[9] Lubliner J, Oliver J, Oller S, Onate E. (1989). A plasticdamage model for concrete. International Journal of solids and Structures 25: 299-326.

[10] Kim, J., LaFave, J. M. (2009). Joint Shear Behavior of Reinforced Concrete Beam Column Connections subjected to Seismic Lateral Loading. NSEL Report Series.

[11] Genikomsou, A. S., Polak, M. A. (2015). Finite element analysis of punching shear of concrete slabs using damaged plasticity model in ABAQUS, Engineering Structures 98: 3848 .

[12] Kim, J., LaFave, J. M. (2007). Key influence parameters for the joint shear behavior of reinforced concrete (RC) beamcolumn connections, Engineering Structures 29: 2523-2539.
[13] American Concrete Institute (ACI). "Building code requirement for structural concrete and commentary". Farmington Hills, Michigan. ACI 318-95. 1995.

[14] ACI 352R-02. (2002). Recommendations for Design of BeamColumn Connections in Monolithic Reinforced Concrete Structures, Reported by Joint ACI-ASCE Committee 352 .

[15] Etemadi E, Fallahnezhad K,. (2017). Behavior of reinforced concrete interior wide beam-column connections under lateral loading: A finite element study. International Journal of Engineering and Technology 9: 2559-2570.

[16] Shin M, LaFave JM. (2004). Modeling of cyclic joint shear deformation contributions in RC beam-column connections to overall frame behavior. Structural Engineering and Mechanics 18 (5): 645-669.

[17] Shayanfar, J., Akbarzadeh Bengar, H., Niroomandi, A. (2016). A proposed model for predicting nonlinear behavior of RC joints under seismic loads, Materials and Design 95: 563-579.

[18] Guo-Lin Wang, Jian-Guo Dai, Teng, J. G. (2012). Shear strength model for RC beam-column joints under seismic loading, Engineering Structures 40: 350-360. 